\title{
Comparison of preservation media and freezing conditions for storage of specimens of faeces
}

\author{
M.DAN*, J.RICHARDSON, M.D.MILIOTIS and H.J.KOORNHOF
}

Department of Microbiology, South African Institute for Medical Research, PO Box 1038, Johannesburg 2000. Republic of South Africa

\begin{abstract}
Summary. To evaluate the long-term recoverability of bacterial enteropathogens, two freezing conditions (deep-freezing at $-70^{\circ} \mathrm{C}$ and liquid nitrogen) and three preservation media (Cary-Blair, Amies, and buffered glycerol-saline) were tested. These were compared with storage in containers with no preservation medium and refrigeration at $4^{\circ} \mathrm{C}$. At $4^{\circ} \mathrm{C}$, viability of organisms could not be consistently maintained beyond one month; Cary-Blair medium generally gave the best results and storage without preservation medium was the least efficient. Storage in liquid nitrogen and deep-freezing effectively preserved all organisms except Campylobacter jejuni for the entire period of study (12 months). There was no difference between the various preservation media, or between storage with or without medium. Storage in preservation medium was superior to storage without such supplement for $C$. jejuni. We conclude that most enteropathogens survive in faecal specimens for as long as 12 months when stored at very low temperatures $\left(-70^{\circ} \mathrm{C}\right)$ whether or not preservation media are used.
\end{abstract}

\section{Introduction}

Techniques for preservation and long-term storage of bacterial isolates are well established, and various methods are available (Amies, 1967). Less experience has been acquired regarding storage of biological specimens that may contain bacterial pathogens. We evaluated the long-term recoverability of various enteropathogens from artificially contaminated human faecal samples after inoculation into three different preservation media, and storage in two different freezing conditions. For comparison, storage in containers with no preservation medium and refrigeration at $4{ }^{\circ} \mathrm{C}$ were also evaluated.

\section{Material and methods}

\section{Bacterial strains}

Eight enteropathogenic species were evaluated: enteropathogenic Escherichia coli (EPEC), Salmonella typhimurium, Shigella flexneri, Shigella sonnei, Campylobacter jejuni, Yersinia enterocolitica, Vibrio cholerae and Aeromonas hydrophila. Two recently isolated strains of each

Received 20 July 1988; accepted 10 Aug. 1988.

* Present address: Infectious Diseases Unit, The Edith Wolfson Medical Center, PO Box 5, Holon 58100, Israel. species were employed; all were isolated originally from human clinical specimens.

\section{Preparation of specimens}

Stools obtained from normal individuals were liquified in sterile water, homogenised by rotation in a Vortex mixer and divided into several aliquots. A known concentration of each individual test strain was inoculated to obtain an average colony count of $2 \times 10^{8} \mathrm{cfu} / \mathrm{g}$ of faeces after final vortex mixing.

\section{Media}

Three preservation media were tested: Cary-Blair medium (Cary and Blair, 1964), Amies medium (Amies, 1967) and buffered glycerol-saline (Teague and Clurman, 1916), contained in $10-\mathrm{ml}$ flasks or $2-\mathrm{ml}$ plastic tubes. Specimens of faeces $(1$ or $0.2 \mathrm{ml})$ seeded with the test strains were added in a proportion of $1: 10$ and then thoroughly emulsified. Specimens were also placed into empty containers (free of preservation medium). Consequently, each test suspension was inoculated into four sets of containers-three with preservations media and one empty.

\section{Storage}

The containers of faecal specimens were stored in three different freezing conditions: refrigerator $\left(4^{\circ} \mathrm{C}\right)$, deep 
freezer $\left(-70^{\circ} \mathrm{C}\right)$, and liquid nitrogen $\left(-196^{\circ} \mathrm{C}\right)$. Sufficient specimens were prepared and stored to allow periodic testing.

\section{Recovery of organisms}

Recovery tests were performed after storage for one week and 1, 3, 6, 9 and 12 months. A loopful of test material was plated on culture medium appropriate to the strain to be recovered (EPEC, MacConkey agar; Shigella and Salmonella spp., SS agar; V. cholerae, TCBS agar; $\boldsymbol{A}$. hydrophila, sheep blood agar with ampicillin $10 \mu \mathrm{g} / \mathrm{ml}$ ). Incubation of plated specimens and identification of isolates were by conventional methods (Lennette et al., 1985).

A crude estimate of quantitative growth of test strains was made according to the following scale; growth over the entire inoculated area, $4+;$ growth over two-thirds of the inoculated area, $3+;>10$ colonies in the primary inoculum area, $2+;<10$ colonies in the primary inoculum area, $1+$.

\section{Results}

The table shows the duration of survival of test organisms in the various storage conditions.

\section{Recovery of bacteria after storage at $4^{\circ} \mathrm{C}$}

Most strains were not viable for more than one week to one month; the exceptions were one of the EPEC strains and one of the Salmonella strains (viability in Cary Blair medium, 5 and 9 months respectively), $V$. cholerae and $A$. hydrophila (viability in Cary Blair and Amies media, 3 and 6 months respectively).

\section{Recovery of bacteria after storage at $-70^{\circ} \mathrm{C}$}

All the enteropathogenic species tested except $C$. jejuni were preserved at $-70^{\circ} \mathrm{C}$ for the entire 12 month-period of study and quantitative recovery was very satisfactory $-4+$ to $3+$. There was no difference between the results obtained with the various preservation media, and between storage with or without media.

C. jejuni was less well preserved: quantitative recovery started to decline at 3 months-score $2+$ to $3+$. At 12 months recovery was best in Amies medium $(2+$ to $3+)$, while in Cary-Blair medium and buffered glycerol-saline it was only $1+$. No organisms were recovered after 12 months from samples stored by deep freezing without preservation medium.

\section{Recovery of bacteria after storage in liquid nitrogen $\left(-196^{\circ} \mathrm{C}\right)$}

Again, the results were less satisfactory for $C$. jejuni than for the other organisms tested. After 12 months, most of the enteropathogenic species were recovered at a score of $3+$ to $4+$, although $S$. flexneri had a somewhat lower score $(2+$ to $3+)$. There was no difference between the various preservation media, or between the use of preservation media and storage in liquid nitrogen alone.

Recovery of $C$. jejuni started to decline after 3 to 6 months. At 12 months, the quantitative recovery was $2+$ to $3+$ for samples stored in preservation media, all of which were equally efficacious. There was practically no recovery of the organism beyond 3 months from samples stored in liquid nitrogen alone.

Table. Viability of enteropathogens in specimens of faeces stored in various freezing conditions and preservation media

Period of survival*

\begin{tabular}{|c|c|c|c|c|c|c|}
\hline \multirow[b]{2}{*}{ Organism } & \multicolumn{4}{|c|}{ Refrigerator $\left(4^{\circ} \mathrm{C}\right)$} & \multirow{2}{*}{$\begin{array}{c}\text { Deep freeze }\left(-70^{\circ} \mathrm{C}\right) \\
\text { (with or without } \\
\text { medium) }\end{array}$} & \multirow{2}{*}{$\begin{array}{c}\text { Liquid } \mathrm{N}_{2}\left(-196^{\circ} \mathrm{C}\right) \\
\text { (with or without } \\
\text { medium) }\end{array}$} \\
\hline & Without medium & Cary-Blair & Amies & BGS & & \\
\hline EPEC & $1 \mathrm{mo}$ & $6 \mathrm{mo}$ & $1 \mathrm{mo}$ & $1 \mathrm{mo}$ & $10 \mathrm{mo}$ & $12 \mathrm{mo}$ \\
\hline Salmonella spp. & 1 wk & $9 \mathrm{mo}$ & $1 \mathrm{mo}$ & $1 \mathrm{mo}$ & $12 \mathrm{mo}$ & $12 \mathrm{mo}$ \\
\hline S. flexneri & 1 wk & $1 \mathrm{wk}$ & 1 wk & $1 \mathrm{mo}$ & $12 \mathrm{mo}$ & $12 \mathrm{mo}$ \\
\hline S. sonnei & $1 \mathrm{wk}$ & $1 \mathrm{mo}$ & 1 wk & $1 \mathrm{mo}$ & $12 \mathrm{mo}$ & $12 \mathrm{mo}$ \\
\hline C. jejuni & $48 \mathrm{~h}$ & $1 \mathrm{mo}$ & $1 \mathrm{mo}$ & $48 \mathrm{~h}$ & $9-12$ mo & $3-12$ mo \\
\hline Yersinia spp. & $1 \mathrm{mo}$ & $1 \mathrm{wk}-1 \mathrm{mo}$ & $1 \mathrm{wk}-1 \mathrm{mo}$ & l wk & $12 \mathrm{mo}$ & $12 \mathrm{mo}$ \\
\hline V. cholerae & 1 wk & $3 \mathrm{mo}$ & $3 \mathrm{mo}$ & 0 & $12 \mathrm{mo}$ & $12 \mathrm{mo}$ \\
\hline Aeromonas spp. & $1 \mathrm{mo}$ & $6 \mathrm{mo}$ & $6 \mathrm{mo}$ & $1 \mathrm{mo}$ & $12 \mathrm{mo}$ & $12 \mathrm{mo}$ \\
\hline
\end{tabular}

BGS, buffered glycerol saline.

*The longest survival times for two strains of each bacterial species tested are recorded. 


\section{Discussion}

The preservation of pathogen viability in biological specimens is essential for their recovery. This is especially true for faecal specimens; overgrowth of normal faecal flora can mask the enteropathogen and impair isolation. In addition, some enteropathogens particularly Shigella spp., are susceptible to acidic changes prompted by overgrowth of intestinal flora.

Several transport media are available for shortterm preservation (Lennette et al., 1985). In a recent paper Wells and Morris (1981) have reported that for isolates of Shigella spp. buffered glycerol-saline was a better transport medium than Cary-Blair medium, and that refrigeration improved the recoverability of the organism from faecal specimen in both transport media. Nevertheless, even when used in conjunction with refrigeration or freezing, the ability of preservation media to support bacterial viability is limited to several days or a few weeks.

For long-term storage, there is some experience of preservation of pure cultures by storage in liquid nitrogen, by deep-freezing, and by freeze-drying (Lapage and Redway, 1974). It is believed that storage in liquid nitrogen is preferable to storage at higher temperatures. This ultra-low temperature storage has been employed successfully to preserve a wide variety of bacterial species. However, it was not known whether this method of preservation was equally efficacious for biological specimens containing micro-organisms. Limited data are available on the viability of $C$. jejuni in stool specimens held in various preservation media and different freezing conditions. In one study (Lenchtefeld et al., 1981), turkey caecal specimens were tested for up to 15 days; the organism survived better at $4^{\circ} \mathrm{C}$ than at $25^{\circ} \mathrm{C}$. Results were improved when transport media were used, the most efficacious being Cary-Blair medium. Poor results $(20 \%$ recoverability) were obtained when specimens were frozen for $24 \mathrm{~h}$ at $-20^{\circ} \mathrm{C}$ or $-70^{\circ} \mathrm{C}$ without transport medium. In another study by the same authors (Wang et al., 1983), stools containing $C$. jejuni from patients with diarrhoea were held in various transport media at $25^{\circ} \mathrm{C}$ or $4^{\circ} \mathrm{C}$. Better

\section{REFERENCES}

Amies C R 1967 A modified formula for the preparation of Stuart's transport medium. Canadian Journal of Public Health 58: 296-300.

Butzler J P, Skirrow M B 1979 Campylobacter enteritis. Clinics in Gastroenterology 8 : 737-765. recoverability of organism was obtained at $4^{\circ} \mathrm{C}$, the best media being alkaline peptone water and modified Cary-Blair medium. Nevertheless, survival of strains did not exceed 3 months.

Long-term preservation of faecal specimens may be especially useful in epidemiological studies when field conditions are not adequate for immediate processing of samples. It can also offer the opportunity to reassess old specimens for new pathogens at a later date.

Our results show that long-term preservation of faecal specimens depends essentially upon storage in very low temperatures rather than an inoculation into specific preservation media. Storage at $-70^{\circ} \mathrm{C}$ and $-196^{\circ} \mathrm{C}$ were equally effective in sustaining viability of enteropathogens throughout the 12 months test period; use of preservation media did not improve the recoverability. This conclusion holds for all bacteria tested except $C$. jejuni. Campylobacter spp. are known to lose viability rapidly, transforming into non-motile coccoid forms which fail to grow on subculture (Butzler and Skirrow, 1979). Nair et al. (1984) were able to preserve a pure culture of this organism for 4 months at $4^{\circ} \mathrm{C}$ in an egg-based medium. We maintained partial viability up to 12 months when stool samples containing $C$. jejuni were inoculated into preservation media and stored at very low temperatures. In contrast, when samples of faeces were kept at $-70^{\circ} \mathrm{C}$ or $-196^{\circ} \mathrm{C}$ without preservation medium, many cultures started to lose viability as early as 3 months, and there was no survival beyond 6-9 months. This trend of reduced recovery when $C$. jejuni was stored in cold temperature without transport medium has also been noted by others (Luechtefeld et al., 1981; Wang et al., 1983).

We conclude that most enteropathogens survive in faecal specimens for as long as 12 months when stored at very low temperatures, whether or not preservation media are used. $C$. jejuni can also be preserved, at least partially, for the same period, if preservation media are used in conjunction with very low temperatures.

M. D. was recipient of a grant from the South African Medical Research Council.

Cary S A, Blair E B 1964 New transport medium for shipment of clinical specimens. I. Fecal specimens. Journal of Bacteriology 88: 96-98.

Lapage S P, Redway K F 1974 Preservation of bacteria with notes on other micro-organisms. Monograph Series No. 7, Public Health Laboratory Service, London.

Luechtefeld N W, Wang W-L L, Blaser M J, Reller L B 1981 
Evaluation of transport and storage techniques for isolation of Campylobacter fetus subsp. jejuni from turkey cecal specimens. Journal of Clinical Microbiology 13: 438-443.

Lennette E H, Balows A, Hausler W J, Shadomy H J (eds) 1985 Manual of clinical microbiology, 4th edn. American Society for Microbiology, Washington D.C.

Nair G B, Chowdbury S, Das P, Pal S, Pal S C 1984 Improved preservation medium for Campylobacter jejuni. Journal of Clinical Microbiology 19 : 298-299.

Teague O, Clurman A W 1916 A method of preserving typhoid stools for delayed examination and a comparative study of the efficacy of eosin-brilliant green agar, eosin-methylene blue agar, and endo agar for the isolation of typhoid bacilli from stools. Journal of Infectious Diseases 18: 653.

Wang W-L L, Reller L B, Smallwood B, Luechtefeld N W, Blaser M J 1983 Evaluation of transport media for Campylobacter jejuni in human fecal specimens. Journal of Clinical Microbiology 18: 803-807.

Wells J G, Morris G K 1981 Evaluation of transport methods for isolating Shigella spp. Journal of Clinical Microbiology 13: 789-790. 